\title{
JUSTIÇA RESTAURATIVA: concepção e interface com a política pública
}

\author{
José Henrique de Góes \\ Universidade Estadual de Ponta Grossa (UEPG) \\ Jussara Ayres Bourguignon \\ Universidade Estadual de Ponta Grossa (UEPG) \\ Paloma Machado Graf \\ Universidade Estadual de Ponta Grossa (UEPG)
}

\begin{abstract}
RESUMO
Este artigo tem como propósito contextualizar a justiça restaurativa no âmbito judiciário brasileiro, explorar sua concepção e demonstrar a sua organização enquanto conjunto de ações, decisões e esforços que se configuram como uma política pública. A realidade brasileira tem sido contexto relevante para implementação de práticas da resolução e/ou transformação de conflitos através de métodos alternativos, sobretudo os mecanismos consensuais, e é nele que se insere a justiça restaurativa. Destaca-se que a justiça restaurativa tem potencial de garantir ao cidadão brasileiro acesso à justiça, consolidando os valores inerentes à democracia ao propiciar mudança cultural, estrutural e institucional, ao começar pela forma de como lidar com os conflitos. Com isso, diante do material analisado, entende-se que a justiça restaurativa pode ser uma ferramenta jurídica que atinge o âmbito social e permite que a mudança ocorra, na medida em que a comunidade é empoderada. Como resultado do presente trabalho, tem-se que a política de justiça restaurativa, em âmbito nacional, vem sendo formulada pelo judiciário, por meio do Conselho Nacional de Justiça $(\mathrm{CNJ})$, para aplicação dos métodos por meio dos tribunais, especialmente a partir de órgãos próprios, enquanto método de solução de conflitos empegado nas esferas pré-processual e processual, com escopo de promoção de acesso à justiça por meio que possibilite consideração de aspectos individuais, comunitários e sociais dos conflitos, em articulação intersetorial e interinstitucional. Trata-se de um estudo de natureza interdisciplinar, fruto de pesquisa exploratória, tendo como fontes bibliografias e documentos da área sócio jurídica.
\end{abstract}

Palavras-chave: Estado. Política pública. Justiça restaurativa.

\section{RESTORATIVE JUSTICE: design and interface with public policy}

\begin{abstract}
This article aims to contextualize restorative justice in the brazilian judiciary, explore its conception and demonstrate its organization as a set of actions, decisions and efforts that are configured as a public policy. The brazilian reality has been a relevant context for the implementation of practices of conflict resolution and / or transformation through alternative methods, especially consensual mechanisms, and it is here that restorative justice is inserted. It should be stressed that restorative justice has the potential to guarantee the brazilian citizen access to justice, consolidating the values inherent to democracy by providing cultural, structural and institutional change, starting with the way of dealing with conflicts. Thus, in view of the material analyzed, it is understood that restorative justice can be a juridical tool that reaches the social realm and allows change to occur, as the community is empowered. As a result of the present work, it has been that the policy of restorative justice, at the national level, has been formulated by the judiciary, through the National Council of Justice for application of the methods through the courts, especially from its own organs,
\end{abstract}


as a method of conflict resolution focused on the pre-procedural and procedural spheres, with the scope of promoting access to justice,through which individual, community and social aspects of conflicts can be considered, in an intersectoral and inter-institutional articulation. It is a study of an interdisciplinary nature, the result of exploratory research, having as sources bibliographies and documents of the legal and social area.

Keywords: State. Public policy. Restorative justice. 


\section{INTRODUÇÃO}

A justiça restaurativa - JR é entendida no âmbito do Judiciário como conjunto de princípios, métodos, técnicas e atividades próprias, utilizados para consideração e solução de conflitos e circunstâncias relacionadas aos conflitos, conforme se depreende do texto do artigo $1^{\circ}$ da resolução 225/2016 do Conselho Nacional de Justiça - CNJ (CNJ, 2016).

A justiça restaurativa, cujo surgimento decorre de diversa narrativas, é um modelo que prepondera a participação dos sujeitos envolvidos em uma situação conflitiva, para que, em consenso, possam tratar acerca da reparação do dano e das necessidades de cada envolvido, junto à comunidade. Sua aplicação em meio judicial remonta aos conjuntos de técnicas e procedimentos utilizados por juízes, voluntários e órgãos relacionados a políticas para crianças e adolescentes em países como Estados Unidos, Canadá, Nova Zelândia. No Brasil, experiências iniciais ocorreram no âmbito do Judiciário em projetos piloto nas cidades de Porto Alegre, São Caetano do Sul e Brasília, em parceria com o Programa das Nações Unidas para o Desenvolvimento - PNUD, entre os anos de 2004 e 2005.

No âmbito nacional brasileiro, a política de JR vem sendo estabelecida dentro do Poder Judiciário a partir do CNJ, inexistindo menção específica à JR em outras normativas de abrangência nacional, exceto pela Lei 12.594/2012 (BRASIL, 2012), que prevê que a execução das medidas socioeducativas se regerá por princípios, sendo um deles a "prioridade a práticas ou medidas que sejam restaurativas e, sempre que possível, atendam às necessidades das vítimas" (artigo 35, inciso III). No âmbito social, há forte movimento legislativo municipal e estadual na promulgação de leis que dispõem sobre programas restaurativos como políticas públicas para o atendimento das comunidades, como pode ser visto, a título de exemplo, pelas normativas municipais, lei de $\mathrm{n}^{\circ}$ 12674/2016 (Ponta Grossa/PR), decreto n² 24647/2016 (Foz do Iguaçu/PR) e lei de n 2685/2017 (Guarapuava/PR), bem como, na normativa estadual pactuada por meio do Convênio de $n^{\circ}$ 007/2016 do Estado do Rio Grande do Sul.

Com intuito de contextualizar a JR no âmbito judiciário brasileiro, o presente artigo explora sua concepção, e, para demonstrar a sua organização enquanto política pública, identifica o conjunto de ações, decisões e esforços previstos para a promoção das práticas restaurativas.

As políticas públicas são programas, ações e atividades desenvolvidas pelo estado, diretamente ou indiretamente, com a participação de entes públicos ou privados, que visam assegurar determinado direito de cidadania, de forma difusa ou para determinada parcela da população, observando as diferentes dimensões dos direitos sociais como a social, cultural, política 
e econômica. As políticas públicas correspondem a direitos assegurados constitucionalmente e que se afirmam a partir de lutas históricas da sociedade civil, buscando garantir demandas concretas dos cidadãos, demandas que se constituem em expressões da questão social.

Frey (2000), descreve três dimensões referente ao debate sobre políticas públicas, as quais são: “[...] uma dimensão institucional (polity), uma dimensão processual (politics) e uma dimensão material (policy/policies)." Destaca-se que a dimensão institucional (polity) refere-se ao ordenamento institucional e jurídico, bem como ao sistema político-administrativo adotado pelo estado. A dimensão processual (politics) envolve as relações entre os diferentes "[...] atores políticos, partidos e agentes do governo [...]", bem como aos "[...] conteúdos e às decisões de distribuição de poderes." Por fim, a dimensão material (policy) demonstra o entendimento sobre os conteúdos das políticas públicas, observando programas e/ou planos de governo e seus resultados concretos. Estas dimensões não são desarticuladas, se inter-relacionam. Especialmente, enfatiza-se a dimensão material (policy/policies) das políticas públicas, visto envolver processos de formulação e implementação das mesmas mediante as demandas da população. Assim

Políticas públicas, tradicionalmente, compreendem o conjunto das decisões e ações propostas geralmente por um ente estatal, em uma determinada área (saúde, educação, transportes, reforma agrária, etc.), de maneira discricionária ou pela combinação de esforços com determinada comunidade ou setores da sociedade civil (TUDE 2010: 11).

O presente artigo objetiva descrever acerca da aplicabilidade da JR como política pública de prevenção criminal e acesso à justiça, base fundante para o desenvolvimento de uma cultura de pacificação social e não violência, em consonância com o atual modelo retributivo, de modo que ambos possam transformar a forma de lidar com os conflitos sociais, que são inerentes à vida em sociedade.

A política de JR formulada pelo Conselho Nacional de Justiça (CNJ) visa à promoção do direito fundamental de Acesso à Justiça, conforme se depreende do texto da resolução 225/2016 (CNJ, 2016a), previsto na Constituição Federal - CF (BRASIL, 1988), em seu artigo 5a, inciso XXXV, interpretado pelo referido órgão como abrangente "do uso de meios consensuais, voluntários e mais adequados a alcançar a pacificação da disputa" (CNJ, 2016a).

Para tanto, procedeu-se a pesquisa exploratória, documental e bibliográfica, a fim de contextualizar a JR no âmbito do Judiciário, articulando sua concepção à identificação de sua organização enquanto conjunto de ações, decisões e esforços, caracterizados de modo específico quanto à sua forma de realização, no intuito de identificar aspectos individuais, comunitários e sociais dos conflitos, em articulação intersetorial e interinstitucional. 
Neste sentido, pretende-se contextualizar a justiça restaurativa no âmbito judiciário brasileiro, explorar sua concepção e demonstrar a sua organização enquanto política pública capaz de trazer mudanças culturais, estruturais e institucionais.

\section{CONCEPÇÃO DE JUSTIÇA RESTAURATIVA E SUA EMERGÊNCIA NA REALIDADE BRASILEIRA.}

De acordo com a literatura internacional (WALGRAVE, 2008; BRAITHWAITE, 2002; ZEHR, 2008; MAXWELL, 2005), há convergência entre alguns pesquisadores de que a justiça restaurativa (JR) ganhou espaço institucional nos Estados Unidos da América, no Canadá, na Nova Zelândia, Austrália e África do Sul a partir das décadas de 1970 e 1980, quando se iniciou uma trajetória judiciária e social com a utilização de técnicas tradicionais herdadas pelas comunidades aborígenes e indígenas, em conjunto com as iniciativas de movimentos sociais contemporâneos que reivindicavam direitos diversos (PINTO, 2005; ZEHR, 2012; CNJ, 2018).

A justiça restaurativa apresenta um modelo diferenciado, em que os indivíduos envolvidos numa situação conflitiva se empoderam ao ponto de solucionar ou transformar o seu próprio conflito, na medida do possível, estabelecendo, em consenso, acerca da reparação dos danos e das necessidades de cada envolvido, com foco na responsabilização ao invés da punição.

Nesse tipo de sistema, todos os indivíduos que estão, direta ou indiretamente, ligados à uma situação conflituosa contribuem e participam da criação de diretrizes e condutas que auxiliam na construção de um senso comunitário e de pertencimento. Ou seja:

O campo, agora, se estende para além do Estado, envolvendo os atores e agências da sociedade civil, permitindo que rotinas de controle do crime sejam organizadas e direcionadas ao largo das agências estatais. O controle do crime está se tornando responsabilidade não só dos especialistas da justiça criminal, mas de todo um conjunto de atores sociais e econômicos (GARLAN 2008: 370).

Van Ness e Strong (apud JACCOUD, 2005), por exemplo, sustentam que a justiça restaurativa tem inspiração também nas sociedades comunais, ou seja, sociedades pré-estatais europeias e coletividades nativas ancestrais, pois estas eram organizadas de modo a privilegiar práticas de regulamento social com foco na harmonia e unidade do grupo e os interesses coletivos se sobressaíam aos individuais, com intuito de manter o equilíbrio e o bem da comunidade. As sanções e castigos também eram presentes como forma de mecanismo de regulamentação, no entanto, a tendência era aplicá-los de forma a manter a estabilidade do grupo social.

Para os referidos autores, pode-se verificar a ocorrência de práticas restitutivas e reintegradoras, por exemplo, no Código de Hammurabi (1700 a. C) e de Lipit- Ishtar (1875 a.C), em 
que determinavam medidas restitutivas para crimes cometidos contra bens móveis/imóveis. Já no Código Cumeriano (2050 a.C.) e o de Eshunna (1700 a.C.), retratavam acerca da possibilidade de restituição em casos de crimes cometidos sob violência. Esse tipo de justiça reintegradora, inclusiva ou restitutiva, também pode ser vista nos povos ancestrais (antes da colonização) na África, da Nova Zelândia, da Áustria, da América do Norte e do Sul, bem como entre as sociedades préestatais da Europa (JACCOUD, 2005). No entanto, tal argumento não é consenso na teoria acadêmica sobre a justiça restaurativa, havendo autores, como por exemplo Achutti que divergem da herança ancestral da justiça restaurativa e a consideram como emergente a partir da década de 1970, com os movimentos sociais pelos direitos civis e direitos humanos, movimentos feministas, comunitarismo, abolicionismo e a criminologia crítica, por exemplo (CNJ 2018: 56).

A despeito das múltiplas influências que propiciaram o surgimento da prática restaurativa, todas elas convergem quanto a preocupações sobre o crime, à crítica ao sistema penal e suas formas de violação de direitos e práticas de injustiça (CNJ, 2018).

Jaccoud (2005) cita Faget (1997) ao justificar que existem três correntes que podem ter favorecido o surgimento da justiça restaurativa nas sociedades ocidentais contemporâneas, quais sejam: 1) a contestação das instituições repressivas, 2) a (re) descoberta da vítima e 3) a exaltação ou o resgate da comunidade.

Nesse sentido, a justiça restaurativa é considerada um movimento social que auxilia na construção de sociedades civis mais coesas e resistentes, que proporcionam maior participação e interação dos cidadãos junto às organizações sociais, ao mesmo tempo em que contribui para o fortalecimento das instituições por meio da cooperação dos cidadãos e entes estatais.

O que se vislumbra com a aplicação da justiça restaurativa é a sinergia entre o estado e a sociedade civil, para que a participação cívica dos cidadãos ultrapasse a questão da criminalidade ou melhoria da qualidade da prestação de serviço social, mas sim, também, ao pleno exercício dos direitos fundamentais com a participação social (OXHORN; SLAKMON, 2005).

Com a finalidade de incentivar e regulamentar a justiça restaurativa, a Organização das Nações Unidas (ONU) emitiu as Resoluções de n 1999/26, 2000/04 e 2002/12 sobre o assunto. No Brasil, a justiça restaurativa foi institucionalizada entre os anos de 2004 a 2009 com a implantação de 3 (três) projetos-pilotos, situados nos Estados do Rio Grande do Sul, São Paulo e Distrito Federal. Porém, já era aplicada por sujeitos alheios às instituições e estuda academicamente desde a década de 1990 (PALLAMOLLA, 2017). Nos anos de 2010 a 2017 houve a normatização do sistema pelo ordenamento jurídico brasileiro, com as Resoluções de $n^{\circ}$ 125/2010 e 225/2016 do CNJ. 
A abordagem restaurativa, como parte integrante do sistema político-social da justiça criminal, surgiu da:

(...) intersecção de linhas de crítica várias da justiça penal. Assentada na idéia de que a justiça penal falhou naqueles que deveriam ser os seus objetivos primeiros: não logra ressocializar ao agente reintegrando-o enquanto cidadão preparado para respeitar as normas; não garante a satisfação das necessidades concretas da vítima, correspondendo mal às suas expectativas de superação dos problemas comuns nem tem conseguido garantir a pacificação de sociedades alarmadas pela violência e pela criminalidade (SANTOS 2008: 36-37).

Trabalha-se com a justiça restaurativa em três dimensões: a) da vítima, a empoderando, pois a partir do momento que sofre uma agressão e o Estado ocupa o seu lugar na persecução e apenas lhe dá status de prova em espécie, ela perde sua autonomia, que certamente não é devolvida pela simples condenação do agressor; b) do ofensor, incutindo nele sentido de responsabilidade e pertencimento, que o sistema tradicional não lhe confere; c) da comunidade, o que implica em uma coesão e integração social (ZEHR, 2012).

Nesse sentido, justiça restaurativa pode ser conceituada como:

(...) um processo através do qual todas as partes interessadas em um crime específico se reúnem para solucionar coletivamente como lidar com o resultado do crime e suas implicações para o futuro (MARSHALL 1990: 5).

(...) toda ação que é primariamente orientada para a justiça, ao restaurar o dano causado por um crime (WALGRAVE 1999: 48).

(...) uma aproximação de justiça centrada na correção dos erros causados pelo crime, mantendo o infrator responsável pelos seus atos, dando diretamente às partes envolvidas por um crime - vitima (s), infrator e coletividade - a oportunidade de determinar suas respectivas necessidades (CORMIER 2002 apud JACCOUD 2005:169).

Portanto, é um processo que envolve, tanto quanto necessário, os indivíduos que têm interesse em determinada situação conflituosa, num processo que, coletivamente, identifica e trata os danos, necessidades e obrigações decorrentes da ofensa, a fim de promover o restabelecimento das pessoas e acertar as coisas, na medida do possível (ZEHR, 2012).

A justiça restaurativa apresenta uma forma diferenciada de lidar com os conflitos, ressignificando o conceito de culpa e punição - trocando-os por responsabilização pelos atos e obrigações em reparar o dano, abstraindo o sentido de negatividade do conflito, tratando-o como algo natural das relações humanas, mas com base na não violência.

Por isso, tem-se que a justiça restaurativa, consequentemente, colabora na implementação de ações afirmativas para o exercício da cidadania e direitos fundamentais em parceria com o Estado, para a adequada prestação dos serviços socioassistenciais, com intuito de garantir a eficiência do atendimento da rede, ao apoiar a mudança dos projetos sociais, preservando a 
dignidade dos sujeitos e atuando na prevenção criminal para o fomento de uma sociedade mais justa, baseadas nos princípios da não violência, da cultura de paz e no empoderamento da sociedade.

A JR aplicada em formas de programas sociais e políticas públicas tem potencial para reduzir as diferenças da estrutura social, tendo em vista que apresenta a justiça de forma mais democrática e acessível, proporcionando uma maior universalidade de tratamento e condições. Dito isso, importante aqui destacar a importância de se aplicar a justiça restaurativa de acordo com as possibilidades de cada localidade e região, posto que as práticas e políticas assumem diferentes formas, tanto em países diferentes como dentro de um mesmo país e, assim, devem ser levadas em consideração as peculiaridades de cada localidade. Uma justiça restaurativa focada nas necessidades e nas possibilidades da região em que é aplicada deve levar em consideração as singularidades, os conhecimentos e as capacidades regionais, bem como, adotar/importar práticas de outros países adaptando-as de acordo com as necessidades locais.

No Brasil, tem-se a emergência de uma justiça de mudança cultural, estrutural e institucional, no entanto ainda encontra barreiras em todos esses aspectos. E, para auxiliar nessa transformação, vê-se na JR um instrumento de mudança jurídico-social, como se nota pelo trabalho realizada pela Justiça Pesquisa do Conselho Nacional de Justiça, intitulada: Pilotando a justiça restaurativa: o papel do poder judiciário, o qual elencou, de acordo com a análise dos projetos restaurativos brasileiros, que a justiça restaurativa tem servido para:

a) A resolução dos conflitos; b) A responsabilização dos ofensores pelos seus atos reinserção social; c) Que os ofensores não reiterem na prática de crimes; d) O empoderamento do ofendido e da comunidade; e) Promover práticas para um convívio mais pacífico e/ou pacificação social; f) Reestabelecer os vínculos comunitários/familiares; e, g) Aprendizado de uma nova forma de relação e transformação das pessoas e das relações (CNJ 2018: 15).

E, assim prossegue em suas considerações finais do estudo realizado que:

- A JR vem avançando significativamente no Brasil, ganhando espaços judiciais e não judiciais muito importantes, acumulando conhecimento e experiência na Justiça juvenil e de adultos e constituindo comunidades restaurativas de qualificada sensibilidade e inteligência humanista. Entretanto, evidenciam-se limites estruturais e contextuais à consolidação da JR como um novo paradigma de justiça no Brasil;

- Quanto ao protagonismo do Judiciário em matéria restaurativa, ele não está só; mas se trata de uma face do denominado "ativismo judicial", cuja base é a politização do Judiciário, no contexto de crise de legitimidade do Estado e da justiça penal e de crise estrutural do capitalismo;

- Embora o campo da JR se apresente como um discurso, no âmbito valorativo principiológico, do humanismo e do pacifismo universalistas, é importante não despolitizar seu horizonte, porque do que se trata aqui é de uma rediscussão sobre um novo ideal de 
Justiça e da forma de reação a condutas e situações. Portanto, sobre poder, controle social e dominação/emancipação;

- Ao protagonizar o processo restaurativo, está em jogo, para o Judiciário, não apenas a requalificação da Justiça, a busca de uma justiça mais legítima e exigente, mas também a redistribuição do poder de fazer justiça, até aqui institucionalizada e por ele monopolizada;

- Trata-se de superar um modelo de poder sobre o outro, para construir um modelo de poder com o outro: o trânsito qualitativo a ser processado é do "acesso" à justiça, à participação e à "vivência" da justiça pelos envolvidos;

- A Justiça restaurativa tem um valor em si, e sua medida genuína de legitimidade direta são as partes.

- Logo, não é uma justiça instrumental para obtenção de outros fins, inclusive o próprio acesso à justiça estatal (SLIDES - CNJ 2018:18 -19).

A justiça restaurativa é orgânica, viva, dinâmica, pode ser modificada e alterada, mas sem perder a sua filosofia e seus princípios e valores básicos.

Assim, tendo em vista que os direitos civis são componentes fundantes da prática da cidadania, a construção de um ideal de justiça mais democrático e acessível, principalmente na emergente situação brasileira de justiça, baseado na emancipação e empoderamento das partes no conflito, proporciona uma mudança na perspectiva atual com o resgate dos princípios da dignidade humana, para ofertar aos cidadãos uma justiça mais igualitária, humana e emancipadora (OXHORN; LAKMON, 2005).

Sabe-se que o poder judiciário se encontra em crise ante o desgaste face à morosidade processual, decorrente da criação de uma cultura de resolução de conflitos litigiosa e processual incapaz de satisfazer de maneira adequada às necessidades dos jurisdicionados. Essa cultura contenciosa decorre da usurpação do estado em relação aos conflitos pessoais, porquanto, quando do seu surgimento, tomou para si o poder e responsabilidade de resolver os conflitos.

Assim, diante desse quadro de resgate das capacidades individuais para emergir a melhor solução ou transformação de um conflito, surge possibilidades restaurativas na realidade brasileira em busca de um cenário que fomente a prática da resolução e/ou transformação de conflitos através de métodos alternativos, sobretudo os mecanismos consensuais, a fim de proporcionar aos jurisdicionados melhor atendimento e respostas perenes para os conflitos.

\section{A POLÍtica PÚBLICA DE JUSTIÇA RESTAURATIVA PARA O JUdiCiÁRIO BRASILEIRO}

As normas jurídicas brasileiras conferem fundamento e limite à aplicação da justiça restaurativa - JR, porém, dada a ausência de lei específica sobre o tema, e o tratamento esparso, 
apenas para permitir ou recomendar o uso de práticas consensuais de solução de conflito ${ }^{1}$ em áreas específicas, há ampla possibilidade de regulamentação por parte do poder judiciário.

A análise da Constituição Federal de 1988 - CF/88 permite entender adequada à oportunidade do direito fundamental de acesso à justiça (previsto no artigo $5^{\circ}$, inciso XXXV) a previsão de práticas consensuais de solução de conflitos, que, quando a natureza das relações entre as partes indica, podem resolver mais adequadamente as demandas, trazendo assim solução ao conflito, e não somente ao processo judicial ${ }^{2}$. Ou seja, se trata da facilitação, por meio de procedimentos diversos, do entendimento entre as partes, a fim de que resolvam seus conflitos e, se possível, determinem solução ao conflito processual também.

Permitem ou recomendam o uso de práticas consensuais de solução de conflito a partir do Judiciário: a lei do Sistema Nacional de Sócio Educação - SINASE, de nº 12.594/2012; o Código Penal, Decreto-Lei de n. 2.848/1940; o Código de Processo Civil, Lei nº 13.105/2015; a Lei dos Juizados Especiais Estaduais, de n. 9099/95; o Estatuto da Criança e do Adolescente - ECA, Lei n. 8069/90, bem como, diversas cartas e resoluções do Conselho Nacional de Justiça e de Fóruns temáticos. A Lei da Mediação, de no 13.140/2015, trata especificamente deste método, porém é marco da utilização do consenso mediado para soluções de conflitos jurídicos.

A Política nacional de conciliação, criada pelo CNJ, por meio da resolução 125/2010, se deu para determinar a implementação, nos Tribunais, de meio consensuais de solução de conflito, mencionando como incumbência de tais órgãos, além da solução mediante sentença, o oferecimento de outros mecanismos de solução de controvérsias, especialmente os consensuais, bem como atendimento e orientação aos cidadãos (BRASIL, 2010).

A resolução determinava a instalação, nos âmbitos dos Tribunais, em trinta dias, de Núcleos permanentes de métodos consensuais de solução de conflitos - NUPEMEC's. Seriam compostos de magistrados e servidores, para desenvolver a política, instalar Centros judiciários de solução de conflitos e cidadania - CEJUSC's, estes responsáveis pela realização das sessões de conciliação e mediação. Ainda, os NUPEMEC's seriam responsáveis por promover a capacitação dos magistrados, servidores e conciliadores e mediadores, bem como por firmar convênios. Os

\footnotetext{
1 A expressão "métodos consensuais de solução de conflito", ao lado de expressões similares como "métodos adequados de solução de conflito" e "métodos alternativos de solução de conflito" designam procedimentos desenvolvidos com o fito de resolver conflitos e/ou reestabelecer relações como alternativa ou solução justaposta a processos judiciais, a partir da facilitação de um terceiro imparcial. Em termos de política pública, são exemplos, conforme o parágrafo único do artigo $1 \circ$ da resolução 125/2010: a conciliação, a mediação.

${ }^{2}$ Neste sentido, o texto do artigo 10 da resolução 125/2010, do CNJ: "Fica instituída a Política Judiciária Nacional de tratamento dos conflitos de interesses, tendente a assegurar a todos o direito à solução dos conflitos por meios adequados à sua natureza e peculiaridade.
} 
CEJUSC's deveriam realizar, preferencialmente, as sessões e audiências de conciliação e mediação, bem como atendimento e orientação ao cidadão (BRASIL, 2010).

Na Emenda n. $1^{\circ}$, de 2013, mencionam-se os procedimentos restaurativos, no artigo 7॰, que versa sobre as atribuições dos NUPEMEC's, referindo que tais órgãos poderiam centralizar e estimular programas de mediação penal ou qualquer outro processo restaurativo, respeitados os princípios básicos previstos na Resolução n. 2002/12 do Conselho econômico e social da Organização das Nações Unidas - ECOSOC/ONU³ (BRASIL, 2013).

Na Emenda n. $2^{\circ}$, de 2016, se estabeleceu que o curso de capacitação básica dos terceiros facilitadores (conciliadores e mediadores) objetiva informações teóricas gerais sobre conciliação e mediação, vivência prática para aquisição do mínimo de conhecimento ao exercício de tais atividades, tendo como parte essencial exercícios simulados e estágio supervisionado (módulo prático) de sessenta a cem horas. O conteúdo programático do módulo teórico, de quarenta horas, envolve: o panorama histórico dos métodos, seu tratamento legal e da política; cultura de paz; teoria da comunicação, dos jogos e do conflito; negociação, conciliação, mediação; interdisciplinaridade na mediação; papel do conciliador/mediador e sua ética; áreas de utilização da conciliação/mediação (empresarial, familiar, civil, penal e justiça restaurativa). No módulo prático, há a previsão de desenvolvimento das atividades com acompanhamento por membro da equipe docente ou autosupervisionado, e desempenho das funções de co-conciliador ou co-mediador e de conciliador ou mediador, com apresentação de relatório ao final das sessões. Os treinamentos poderão ser flexibilizados pelo instrutor, atendendo as especificidades da mediação por ele adotada, com ênfase a uma ou outra área (BRASIL 2016).

Em 2005, por iniciativa, também, da antiga Secretaria de Reforma do Judiciário, do Ministério da Justiça, foram implementados três projetos-piloto, no Núcleo Bandeirante (Distrito Federal), em São Caetano do Sul (São Paulo), e em Porto Alegre (Rio Grande do Sul). O projeto "Promovendo práticas restaurativas no sistema de justiça brasileiro" (PNUD/Ministério da Justiça), em Porto Alegre, foi desenvolvido com foco nos processos judiciais da $3^{\mathrm{a}}$ Vara da Infância e Juventude de Porto Alegre, Rio Grande do Sul. A contribuição da UNESCO/Criança Esperança, que a partir de agosto deu lugar à execução do Projeto "Justiça para o século 21", expandiu a difusão e aplicação da justiça restaurativa ao atendimento técnico dos adolescentes que cometeram ato infracional.

\footnotetext{
3 A resolução dispõe que processo restaurativo significa: "qualquer processo no qual a vítima e o ofensor, e, quando apropriado, quaisquer outros indivíduos ou membros da comunidade afetados por um crime, articipam ativamente na resolução das questões oriundas do crime, geralmente com a ajuda de um facilitador. Os processos restaurativos podem incluir a mediação, a conciliação, a reunião familiar ou comunitária (conferencing) e círculos decisórios (sentencing circles)".
} 
Na resolução 225/2016, se estabeleceu a Política Nacional de JR no âmbito do Poder Judiciário, por meio do CNJ, que, para tanto, considerou, conforme se depreende do texto da resolução, além de suas atribuições regimentais (dentre as atribuições, estão aquelas para produzir estatística sobre processos, propor medidas para celeridade, desburocratização e eficiência, estabelecer metas (BRASIL, 2009), as resoluções da ONU sobre a matéria. As resoluções do Conselho econômico e social da ONU versam sobre elaboração e aplicação de medidas de mediação e JR em matéria criminal (1999/26), e sobre princípios básicos para utilização de JR em matéria criminal $(2000 / 14,2002 / 12)$.

A resolução 225/2016 define a JR como conjunto de princípios, métodos, técnicas para conscientização sobre fatores de conflitos e violência, pelo qual se solucionam conflitos que geram dano, de forma: a contar com a participação do ofensor, da vítima, suas famílias e demais envolvidos no fato, bem como com a presença de representantes comunitários e de pelo menos um facilitador capacitado em técnicas da JR (podendo ser indicado por entidades parceiras, voluntário ou agente público); a objetivar a satisfação das necessidades dos envolvidos, a responsabilização ativa de quem contribuiu para o fato e o empoderamento comunitário, com reparação do dano.

Também define prática restaurativa como "forma diferenciada de tratar as situações" de conflito, e procedimento restaurativo como "conjunto de atividades e etapas a serem promovidas objetivando a composição das situações" de conflito. Especifica a expressão "enfoque restaurativo" como "abordagem diferenciada das situações" de conflito ou dos "contextos a elas relacionados, compreendendo a participação dos envolvidos, suas famílias e comunidades; "atenção às necessidades legítimas da vítima e do ofensor"; reparação dos danos; compartilhamento de responsabilidades e obrigações entre os participantes para superação das causas e consequências do ocorrido.

O documento estabelece que o procedimento pode ocorrer alternativa ou concorrentemente ao processo convencional, considerando-se as necessidades dos envolvidos e o sistema processual legal. Estabelece como princípios orientadores da JR: a "corresponsabilidade"; a reparação dos danos; o atendimento às necessidades dos envolvidos; a informalidade; a voluntariedade; a imparcialidade; a participação; o empoderamento; a consensualidade; a confidencialidade; a celeridade; a urbanidade.

Ainda, estabelece a necessidade de reconhecimento dos fatos essenciais ao conflito como verdadeiros, "sem que isso implique admissão de culpa em eventual retorno do conflito ao processo judicial". 
Quanto às competências, atribui ao CNJ competência para organizar programa para incentivo à JR, pautado pelo caráter: universal, de acordo com o interesse dos usuários do Judiciário; sistêmico, buscando a integração das redes familiares e comunitárias, bem como das políticas relacionadas à causa ou a sua solução; institucional, contemplando cooperação para promoção da JR nas instituições afins, na academia e organizações da sociedade civil; interdisciplinar, com estratégias para agregar o conhecimento das áreas afins aos fenômenos relacionados à JR; intersetorial, para colaboração das demais políticas, especialmente segurança, assistência, educação e saúde; formativo, contemplando multiplicadores de facilitadores em JR; de suporte, prevendo mecanismos para monitoramento, pesquisa, avaliação, com base de dados.

Também, a resolução prevê a implementação da JR com participação dos órgãos do Poder Judiciário e entidades públicas e privadas parceiras, inclusive instituições de ensino. Dá aos Tribunais de Justiça competência para implementação dos programas de JR, coordenados por órgão organizado para tal fim, com magistrados e equipe técnico-científica, para: desenvolver plano de implementação da JR; dar consecução aos objetivos da resolução, atuar na interlocução com a rede de parcerias; incentivar ou promover capacitação permanente de magistrados, servidores e voluntários dos procedimentos, com respostas a situações de vulnerabilidade e atos infracionais em articulação com a rede de garantia de direitos; promover a criação e instalação de espaços de serviço para atendimento restaurativo; estabelecer parcerias ou disponibilizar recursos humanos e materiais para instalação do programa, com facilitadores e equipe técnica interdisciplinar com psicólogos e assistentes sociais, por exemplo, para auxiliar os facilitadores, sempre que possível.

A resolução possibilita o encaminhamento, para atendimento judicial, de procedimentos e processos judiciais, em qualquer fase de tramitação, pelo juiz, de ofício o a requerimento do Ministério Público, da Defensoria Pública, das partes, de seus advogados, dos setores técnicos de psicologia e serviço social, com possibilidade de sugestão por policiais.

Determina-se a coordenação das reuniões e procedimentos relacionados pelo facilitador, especificando os "trabalhos de escuta e diálogo entre os envolvidos", por meio da utilização dos métodos da JR, devendo ressaltar o sigilo, a confidencialidade, voluntariedade, entendimento das causas do conflito, suas consequências, e o valor social da norma violada pelo conflito.

Prevê-se a realização de termo contendo: breve memória da sessão, com nomes dos presentes; plano de ação com acordos eventualmente estabelecidos; preservação do sigilo e confidencialidade em relação ao ocorrido na sessão, exceto questões acordadas entre as partes, exigências legais ou situações que coloquem em risco a segurança dos participantes. 
Dispõe-se a possibilidade de proposição de plano de ação com orientações, sugestões e encaminhamentos que visem á não recidiva do fato danoso, ainda que não havido acordo para a solução do conflito.

Os acordos deverão ser homologados judicialmente, sendo, nos casos pré-processuais (não submetidos a juiz por meio de processo judicial, facultativo o envio à homologação.

Quanto aos facilitadores (terceiros, não participantes dos conflitos), determina-se a necessidade de formação por meio de curso de capacitação, e de aperfeiçoamento permanente, baseado nas demandas verificadas em formulários disponibilizados a participantes de sessões restaurativas. São suas atribuições, previstas no documento: preparação dos encontros; abertura e condução propiciando espaço de compreensão do conflito em sua amplitude, por meio das técnicas próprias com estímulo ao diálogo e reflexão do grupo, a desencadear ações coordenadas para não reiteração do ato danoso ou de suas condições; atuação respeitosa e que considere situações de hipossuficiência; consideração dos fatores institucionais e sociais que contribuíram para o surgimento do fato ou dos danos, indicando necessidade de sua eliminação ou diminuição; redação do termo de atestado de insucesso ou de acordo; incentivo ao grupo para promoção de adequações ou encaminhamentos no aspecto social e comunitário, com articulações com a Rede de garantia de direitos local.

A promoção dos referidos cursos é de atribuição dos tribunais, por escolas judiciais e da magistratura, sendo referidos como cursos de "capacitação e aperfeiçoamento", com estruturação do plano pedagógico básico, considerando os dados obtidos; com formadores de experiência comprovada em capacitação na área e atestados de realização de procedimentos e atuação em projetos relacionados à JR; conteúdo programático com número de exercícios simulados e carga horária mínima conforme deliberado pelo Comitê Gestor da JR, contendo estágio supervisionado como estabelecido pelas escolas da magistratura e judiciais; com alunos técnicos ou não técnicos oriundos das comunidades, inclusive indicados por parceiros.

Conferiu-se autonomia aos tribunais para parâmetros curriculares para os cursos, com número de exercícios simulados, carga horária mínima e estágio supervisionado.

Ainda, atribui-se o dever dos tribunais de acompanhamento e suporte aos projetos, para cumprimento dos princípios básicos e balizas da resolução; manutenção de banco de dados sobre as atividades da JR. Ao CNJ, a compilação de informações sobre os projetos e seu desempenho, promovendo estudos para elaboração de plano disciplinar básico para a formação em JR junto às escolas judiciais e da magistratura. 
Quanto à formação, até o fim de 2016, não havia regulamentação específica do CNJ para a formação de instrutores e capacitação de facilitadores, tendo sido a redação da resolução, quanto a ficar a cargo de cada tribunal o conteúdo programático, proposta pelo grupo de trabalho de JR (TJPR, 2017).

Além da resolução 225/2016, e respeitando suas disposições, bem como as especificidades de cada área do direito e da legislação correspondente, órgãos do Poder Judiciário ${ }^{4}$ podem regulamentar a utilização da JR em seu âmbito.

O Conselho Nacional de Justiça, em 2014, firmou parceria com a Associação dos magistrados brasileiros para propagar a JR, por Protocolo de cooperação para a difusão da justiça restaurativa, articulando vinte instituições federais, agências da ONU e organizações nãogovernamentais, para desencadear movimento nacional, incluindo formalização de parcerias institucionais e acadêmicas, capacitação pela Escola Nacional da Magistratura (AMB, 2014). Em 2016, a definiu como meta para a justiça estadual (BRASIL, 2016): inclusão formal de programa de JR; destinação de espaço físico para atendimento aos envolvidos; oferecimento de condições materiais à realização do encontro; disponibilização de recursos humanos para os procedimentos; a realização de capacitação e treinamento para desenvolvimento das competências profissionais ao procedimento; promoção de encontros aos envolvidos para incentivo à reparação do dano e resgate de relações; atendimento para pessoas indiretamente atingidas pelos conflitos, como famílias dos envolvidos.

Sete tribunais de justiça (de vinte e sete) cumpriram cem por cento da meta até setembro de 2016, implementando pelo menos uma unidade para JR: Acre, Distrito Federal, Minas Gerais, Paraná, Mato Grosso, Mato Grosso do Sul e Rio Grande do Sul. (CNJ, 2016)

O Tribunal de Justiça de São Paulo deu início ao projeto de justiça restaurativa em 2005, nas varas da Infância e da Juventude da capital, e em escolas de comunidades carentes da capital e do paulista. Um dos pioneiros nas práticas restaurativas no Brasil, o Tribunal de Justiça do Rio Grande do Sul estava com vinte e duas unidades judiciárias de JR, tendo passado pelo processo de “sensibilização" novecentos e um servidores, sendo cem deles em 2016. O tribunal implementou o "Programa justiça restaurativa" para o século 21, por iniciativa da Corregedoria-Geral, em novembro de 2014, com ações planejadas para utilização do método (CNJ, 2016).

No Paraná, a pioneira Ponta Grossa iniciou em 2014 a capacitação para juízes e servidores, ministrada pela Escola Superior da Magistratura do Rio Grande do Sul. O núcleo de justiça restaurativa da Bahia, desde 2010 atua em parceria com voluntários. O programa de JR Juvenil de 
Campo Grande, Mato Grosso do Sul atua desde 2010, fruto de parceria entre o Tribunal de Justiça do Estado e do Governo do Estado. (CNJ, 2016)

A discussão sobre a possibilidade da utilização em alguns órgãos está se dando de acordo com parâmetros relativos à natureza das relações em área do direito. Por exemplo, discute-se a possibilidade e adequação da utilização da JR no direito do trabalho, considerando as especificidades da hipossuficiência do trabalhador. A possibilidade de utilização de outros meios autocompositivos mediados por terceiro no âmbito da justiça do trabalho já avançou para projetos piloto no caso da mediação, por exemplo, em alguns tribunais e juízos, como no caso do Tribunal Regional do Trabalho da $9^{\text {a }}$ Região, que abrange o Paraná, em que há Centro Judiciário de Métodos Consensuais de Solução de Disputas - CEJUSC, instituído pela RA 58/2017, do tribunal pleno, publicada no DEJT de 02/06/2017.

Em outros órgãos, a instalação dos centros destinados à resolução consensual de conflitos é realidade mais antiga, porém a implementação das práticas restaurativas é realidade em Tribunais Estaduais, o que é compreensível ante a natureza das demandas de sua competência, que envolvem questões familiares e comunitárias, por exemplo.

A política, portanto, se baseia em diretrizes internacionais de configuração da JR, tendo se desenvolvido em normatização paripassu ao desenvolvimento de experiências desenvolvidas no âmbito de alguns Tribunais de Justiça, com a contribuição de instituições de ensino, profissionais integrantes de equipes técnicas de órgãos do poder judiciário e do executivo, bem como voluntários da comunidade. Nacionalmente, a direção institucional, por parte do Judiciário, se deu em acordo com organização represente dos magistrados, permitindo e incentivando a realização da política como projeto conjunto.

\section{CONSIDERAÇÕES FINAIS:}

A justiça restaurativa, enquanto política do judiciário brasileiro, foi criada considerando incentivo de normativa internacional sobre novas formas de resolução de conflito, visando à garantia do direito de Acesso à Justiça, em vertente que enfatiza a adequação instrumental em atenção às especificidades dos casos. A disseminação das práticas se deu por regulamentação do CNJ, com enfoque na justiça estadual, a partir da criação de estruturas equiparadas a unidades judiciárias (CEJUSC's), com a incumbência de realizar práticas consensuais de solução de conflito.

Os documentos do CNJ determinam as regras mínimas para realização dos procedimentos, estabelecendo, ainda, atribuições dos tribunais, parâmetros de avaliação da política. A formação dos 
facilitadores, seu recrutamento, as espécies de procedimento restaurativo a ser utilizados ganham especificidade a cargo dos tribunais.

Acordos entre entidades que promovem formação de profissionais do direito, órgãos da Administração Pública e do Poder Judiciário, bem como apoio de voluntários e de entidades da sociedade civil são previstas na política, e acompanharam tanto a implementação dos primeiros serviços nos CEJUSC's quanto às ações de divulgação e formação de facilitadores.

Por meio das práticas restaurativas é possível um atendimento diferenciado aos cidadãos, para que se cuide das suas necessidades por meio da análise do contexto social em que o delito foi cometido, a fim de empoderar as partes e que o autor do fato possa reparar os danos, na medida do possível. Essa quebra de paradigma de controle social e de política criminal apresenta um retorno diferenciado a todos os envolvidos e, em especial, à comunidade brasileira, que é resgatada e emancipada, reconhecida como vítima secundária e também responsável pelos seus cidadãos, ensejando assim, senso de pertencimento e unicidade, baseado nos fundamentos de Estado Democrático e Social de Direito, reforçando a cidadania e a dignidade da pessoa humana.

Como resultado das reflexões presentes neste artigo, apresenta-se o desenho institucional pretendido pela política para a promoção do Acesso à Justiça por meio da implementação da JR pelo Judiciário, a fim de resolver conflitos de maneira a considerar e dar resposta a circunstâncias individuais, comunitárias e sociais, com recursos desses mesmos matizes.

A política determina seu desenvolvimento de maneira intersetorial e interdisciplinar, utilizando as redes familiares e comunitárias, pretendendo que a solução do conflito tenha disponíveis recursos consistentes em: modo diferenciado de estabelecimento de diálogo entre os indivíduos diretamente envolvidos no conflito, por meio de facilitador capacitado em cursos promovidos ou reconhecidos por órgãos dos Tribunais; encaminhamentos dos órgãos promotores das reuniões em que desenvolvidas as práticas restaurativas a órgãos ligados a outras políticas (como saúde, educação, assistência social), a fim de suprir demandas relacionadas a condições dos envolvidos que possam ser consideradas relacionadas ao conflito; participação, nas reuniões, de membros da comunidade local de relacionamento dos envolvidos em conflito, bem como de suas famílias, a fim de contribuir no entendimento das circunstâncias e de propiciar ou sugerir possibilidades de solução e prevenção do conflito.

Desta maneira, verifica-se uma articulação entre o referido desenho da política e o conceito de JR utilizado no documento de referência, a resolução $n^{\circ} 225 / 2016$, que considera a JR como conjunto de princípios, métodos, técnicas e atividades próprias para conscientização sobre os fatores 
relacionais, institucionais e sociais motivadores de conflitos e violência, pelo qual os conflitos são solucionados.

Os princípios insculpidos na resolução e referidos neste artigo se referem ao modo articulado pelo qual os órgãos dos tribunais se encarregam de determinar e garantir que os casos de conflito encaminhados por órgãos de outros setores ou do judiciário sejam tratados em reuniões nas quais representantes das comunidades e/ou da família possam aventar soluções para o conflito e para circunstâncias a ele relacionadas. Ainda, para que, em relação a estas, possam ser encaminhadas demandas a órgãos de outros setores, com políticas próprias.

Para utilizar a justiça restaurativa como ferramenta de emancipação dos envolvidos no conflito e de geração de senso comunitário com intenção de construir uma sociedade mais pacífica, calcada em políticas que realmente satisfaçam as necessidades de seus cidadãos, necessário o envolvimento de várias dimensões dos setores públicos, para que oportunizem o acesso à uma justiça construída comunitariamente. Para isso, utiliza-se de uma perspectiva global, em sentido macro, envolvendo todos os sujeitos direta e indiretamente impactados pelo conflito, sendo necessário, portanto, políticas sociais voltadas ao atendimento dos cidadãos e de redes de proteção social para o atendimento adequado às demandas sociais expostas pelo conflito.

Para finalizar, ressalta-se que as práticas restaurativas vêm sendo utilizadas como ferramentas no contexto de diversas políticas públicas para enfrentamento de questões que envolvem a garantia dos direitos sociais das crianças e dos adolescentes em situação de vulnerabilidade ou risco social, por meio da Lei do SINASE, em relação à mulher em situação de violência doméstica e familiar que se encontra em situações de conflitos e fragilidade de vínculos, por meio de projetos realizados pelas varas de violência doméstica, conforme autorizado pela “Carta da XI Jornada da Lei Maria Penha" assinada na cidade de Salvador - BA em 18 de agosto de 2017 pelo CNJ, bem como, autorizados por leis municipais e estaduais que elencam a justiça restaurativa como política pública.

Também, estas práticas avançam para a comunidade, buscando junto à rede de serviços socioassistenciais alternativas para os conflitos comunitários de forma a potencializar os serviços ofertados nos territórios de abrangência das políticas de saúde, assistência social, educação, cultura, entra outras. Portanto, se configura uma potencial ferramenta para os profissionais que atuam em equipes multiprofissionais em diversas políticas públicas. 


\section{REFERÊNCIAS}

AMB. Associação dos Magistrados Brasileiros. Protocolo de cooperação interinstitucional para difusão da justiça restaurativa. 2014. Disponível em: http://www.amb.com.br/jr/docs/protocolo.pdf. Acesso em: 21 mar 2018.

BRASIL. Constituição da República Federativa do Brasil de 1988. Disponível em: http://www.planalto.gov.br/ccivil_03/constituicao/constituicaocompilado.htm. Acesso em: 21 mar. 2018.

Projeto de lei 7006 de 2006. Propõe alterações no Decreto-Lei $\mathrm{n}^{\circ} 2.848$, de 7 de dezembro de 1940, do Decreto-Lei $n^{\circ} 3.689$, de 3 de outubro de 1941, e da Lei $n^{\circ} 9.099$, de 26 de setembro de 1995, para facultar o uso de procedimentos de Justiça restaurativa no sistema de justiça criminal, em casos de crimes e contravenções penais. Disponível em: https://www.lexml.gov.br/urn/urn:lex:br:camara.deputados:projeto.lei;pl:2006-05-10;7006. Acesso em 21 mar. 2018.

. Decreto-Lei de n. 2.848, de 7 de dezembro de 1940. Código Penal. Disponível em: http://www.planalto.gov.br/ccivil_03/decreto-lei/Del2848.htm. Acesso em: 21 mar. 2018.

. Lei 8.069, de 13 de julho de 1990. Dispõe sobre o Estatuto da Criança e do Adolescente e dá outras providências. Disponível em: http://www.planalto.gov.br/ccivil_03/leis/18069.htm. Acesso em: 21 mar. 2018.

. Lei 9.099, de 26 de setembro de 1995. Dispõe sobre os Juizados Especiais Cíveis e Criminais e dá outras providências. Disponível em: http://www.planalto.gov.br/ccivil_03/leis/L9099.htm. Acesso em: 21 mar. 2018.

Lei 12.594/2012, de 18 de janeiro de 2012. Institui o Sistema Nacional de Atendimento Socioeducativo (Sinase), regulamenta a execução das medidas socioeducativas destinadas a adolescente que pratique ato infracional; e altera as Leis nos 8.069, de 13 de julho de 1990 (Estatuto da Criança e do Adolescente); 7.560, de 19 de dezembro de 1986, 7.998, de 11 de janeiro de 1990, 5.537, de 21 de novembro de 1968, 8.315, de 23 de dezembro de 1991, 8.706, de 14 de setembro de 1993, os Decretos-Leis nos 4.048, de 22 de janeiro de 1942, 8.621, de 10 de janeiro de 1946, e a Consolidação das Leis do Trabalho (CLT), aprovada pelo Decreto-Lei no 5.452, de 1o de maio de 1943. Disponível em: http://www.planalto.gov.br/ccivil_03/_ato2011-2014/2012/lei/112594.htm. Acesso em: 21 mar. 2018.

Lei 13.105, de 16 de março de 2015. Código de Processo Civil. Disponível em: http://www.planalto.gov.br/ccivil_03/_ato2015-2018/2015/lei/113105.htm. Acesso em: 21 mar. 2018.

CONSELHO NACIONAL DE JUSTIÇA. Emenda n. 1, de 31 de janeiro de 2013. Altera os arts. $1 \mathrm{o}, 2^{\circ}, 60,7^{\circ}, 8^{\circ}$ 9o, 10,12, 13,15, 16, 18 e os Anexos I, II, III e IV da Resolução n ${ }^{\circ} 125$, de 29 de novembro de 2010 Disponível em: https://juslaboris.tst.jus.br/bitstream/handle/20.500.12178/28620/2013_emenda0001_res0125_2010 _cnj.pdf? sequence=2\&isAllowed=y. Acesso em: 21 mar. 2018.

. Emenda n. 2, de 8 de março de 2016. Altera e acrescenta artigos e os Anexos I e III da Resolução 125, de 29 de novembro de 2010. Disponível: 
http://www.cnj.jus.br/files/conteudo/arquivo/2016/03/d1f1dc59093024aba0e71c04c1fc4dbe.pdf. Acesso em: 21 mar. 2018.

Regimento Interno, 2009. Disponível em: http://www.cnj.jus.br/files/conteudo/arquivo/2015/10/b8953e0554207c0f4fb95a29e9326532.pdf. Acesso em: 21 mar. 2018.

Metas Nacionais 2016. Disponível em: http://www.cnj.jus.br/files/conteudo/arquivo/2016/03/f2ed11abc4b5ddea9f673dec7fe39335.pdf. Acesso em: 21 mar. 2018.

- Relatório Metas Nacionais do Poder Judiciário: 2016. Disponível em: http://www.cnj.jus.br/files/conteudo/arquivo/2017/04/ad0802bb34e1a61b001d00d8c52ecff9.pdf Acesso em: 21 mar. 2018.

Resolução 125 de 2010. Dispõe sobre a Política Judiciária Nacional de tratamento adequado dos conflitos de interesses no âmbito do Poder Judiciário e dá outras providências. Disponível em: http://www.cnj.jus.br/busca-atos-adm?documento=2579. Acesso em: 21 mar. 2018.

Resolução 225 de 2016. Disponível em:

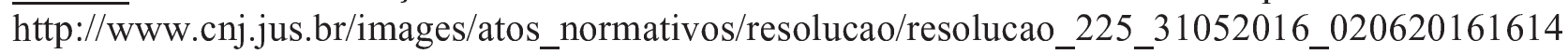
14.pdf. Acesso em: 21 mar. 2018.

. Justiça Pesquisa. Pilotando a Justiça Restaurativa: o papel do Poder Judiciário. Presidente Ministra Cármen Lúcia Antunes Rocha, 2018a. Disponível em: http://www.cnj.jus.br/files/conteudo/arquivo/2017/10/552d371330ac678e682e18267e4dd440.pdf. Acesso em: 5 fev. 2019.

FREY, K. 2000. Políticas públicas: um debate conceitual e reflexões referentes à prática da análise de políticas públicas no Brasil. Planejamento e políticas públicas, Rio de Janeiro, Instituto de Pesquisa Econômica Aplicada (IPEA), n. 21, p. 211-259, ISSN 0103-138.

GARLAND, David. 2008. André Nascimento (trad.). A cultura do controle: crime e ordem social na sociedade contemporânea. Rio de Janeiro: Ed. Revan. ICC. 370 p.

JACCOUD, Mylène. 2005. Princípios, tendências e procedimentos que cercam a justiça restaurativa. In: BASTOS, Márcio Thomaz; LOPES, Carlos; RENAULT, Sérgio Rabello Tamm (orgs.). Justiça restaurativa: coletânea de artigos. Brasília: MJ E PNUD. 479 p.

MARSHALL, T.F. 1999. Restorative justice an overview. London, UK, home office, research development and statistics directorate. 36 p. $\quad$ Disponível em: http://www.antoniocasella.eu/restorative/Marshall_1999-b.pdf. Acesso em: 21 mar. 2018.

OXHORN, P. e SLAKMON, C. 2005. Micro justiça, desigualdade e cidadania democrática. A Construção da sociedade civil através da justiça restaurativa no Brasil. In: BASTOS, Márcio Thomaz; LOPES, Carlos; RENAULT, Sérgio Rabello Tamm (orgs.). Justiça restaurativa: coletânea de artigos. Brasília: MJ E PNUD. 479 p. 
PALLAMOLLA, Raffaella da Porciuncula. A construção da justiça restaurativa no Brasil e o protagonismo do poder judiciário: permanências e inovações no campo da administração de conflitos. 2017. 286 f. Tese (Doutorado em Ciências Sociais) - Escola de Direito, Universidade Católica do Rio Grande do Sul, Porto Alegre, 2017.

SANTOS, Cláudia. 2008. A mediação penal: uma solução divertida? In: Franco, Alberto Silva et al (orgs.). Justiça penal portuguesa e brasileira: tendências e reforma. São Paulo: IBCCRIM. p.3142.

TRIBUNAL DE JUSTIÇA DO DISTRITO FEDERAL E DOS TERRITÓRIOS- TJDFT. TJDFT: história e trajetória. Brasília, 2006. Disponível em: http://www.tjdft.jus.br/publicacoes/edicoesespeciais/livros/tjdft.pdf. Acesso em: 21 mar. 2018.

TJPR. Tribunal de Justiça do Paraná. Comissão de Práticas Restaurativas. Relatório descritivo das atividades da comissão de práticas restaurativas do Tribunal de Justiça do Paraná. 2017. Disponível em: https://www.tjpr.jus.br/documents/14797/7836487/Relat\%C3\%B3rio+Geral+das+Atividades+$+2014+a+2016+$ recebido+em+09-01-2017.pdf/7b1b2238-ef99-430d-9c63-38dca994592d. Acesso em: 21 mar. 2018.

TRT 9. Tribunal Regional do Trabalho da 9a região. Tribunal Pleno. RA 58/2017. Institui o Centro Judiciário de Métodos Consensuais de Solução de Disputas. Disponível em: https://www.trt9.jus.br/portal/pagina.xhtml?secao=22\&pagina=RESOLUCAO. Acesso em: 06 ago. 2019.

TUDE, João Martins. 2010. Conceitos gerais de políticas públicas. In: TUDE, João Martins; FERRO, Daniel; SANTANA, Fabio Pablo (Org.). Políticas públicas. Curitiba: IESDE Brasil S.A. $144 \mathrm{p}$.

WALGRAVE, Lode. 2006. Imposição da restauração no lugar da dor: reflexões sobre a reação judicial ao crime. In: Slakmon, Catherine; Machado, Maíra Rocha; Bottini, Pierpaolo Cruz (Orgs.). Novas direções na governança da justiça e da segurança. Brasília, Ministério da Justiça. Disponível em: https://www.cejamericas.org/Documentos/DocumentosIDRC/156JuizadosEspeciaisoprocessoinexor aveldamudanca.pdf. Acesso em: 12 nov. 2017.

ZEHR, Howard. 2012. Justiça restaurativa. Tônia Van Acker (trad.). São Paulo: Palas Athena. 92 p. 2008. Trocando as lentes: um novo foco sobre o crime e a justiça. Tônia Van Acker (trad.). São Paulo: Palas Athena. 336 p.

\section{AUTORES:}

José Henrique de Góes

Universidade Estadual de Ponta Grossa (UEPG)

E-mail: henriquedegoes@hotmail.com

\section{Jussara Ayres Bourguignon}

Universidade Estadual de Ponta Grossa (UEPG)

E-mail: juaybo@gmail.com 
GÓES, José Henrique de

BOURGUIGNON, Jussara Ayres

GRAF, Paloma Machado

Paloma Machado Graf

Universidade Estadual de Ponta Grossa (UEPG)

E-mail: palomagraf@hotmail.com
JUSTIÇA RESTAURATIVA: CONCEPÇÃO E

INTERFACE COM A POLIÍCA PUBLICA

Recebido em 14/02/2019.

Aceito em 18/07/2019. 